\title{
Surgical treatment of hypertrophic obstructive cardiomyopathy in the elderly
}

\author{
Kalman KafeTZ \\ B.Sc., M.R.C.P.(U.K.) \\ Department of Geriatric Medicine, Hammersmith Hospital, Du Cane Road, London W12 OHS
}

\begin{abstract}
Summary
Three elderly patients with hypertropic obstructive cardiomyopathy which was successfully treated by surgery are described. The role of surgery in the management of older patients with this condition is discussed.
\end{abstract}

\section{Introduction}

Successful cardiac surgery in the elderly is a practical proposition nowadays. The commonest indication for this is fixed obstruction to left ventricular ejection due to aortic valve disease (de Bono, English and Milstein, 1978; Hochberg et al., 1977). Left ventricular outflow obstruction can also occur owing to hypertrophic obstructive cardiomyopathy. Surgery can relieve this obstruction and operation may be indicated if the subvalvar gradient within the left ventricle is greater than $50 \mathrm{mmHg}$ at rest (Goodwin, 1979; Wynne and Braunwald, 1980). However, the role of surgery in the management of this condition is controversial. Mason et al. (1978) in the United States have advocated it enthusiastically while McKenna et al. (1979) in the United Kingdom have suggested that surgery is one of the factors associated with a poor prognosis. Hypertrophic cardiomyopathy is being more commonly recognized in the elderly both in life (Krasnow and Stein, 1978; Berger, Rethy and Goldberg, 1979) and at post-mortem (Pomerance and Davies, 1975). Koch et al. (1980) in the United States have recently reviewed their experience with surgical treatment of this condition in the elderly. They concluded that surgery is as valuable in the management of older patients with this condition as it is in younger patients (Mason et al., 1978). The successful surgical treatment of this condition in 3 elderly patients in the United Kingdom is now reported and the role of surgery in the management of older patients as compared to younger patients is discussed.

\section{Case reports}

Case 1

A 74-year-old woman presented with 6 months of breathlessness which severely limited her exercise tolerance, 3 weeks of angina on slight exertion and one unpleasant attack of rapid palpitations at rest3. She had no other symptoms. She had known that she had a heart murmur for a number of years and there was no family history of cardiovascular disease. On examination she had a pulse of normas quality and a BP of $190 / 90 \mathrm{mmHg}$. She was not in cardiac failure. There was clinical evidence of marked left ventricular hypertrophy and an ejection systolic murmur was heard all over the praecordiums Chest X-ray showed an enlarged heart, clear lung\$ and mitral valve calcification. Electrocardiogran? (ECG) showed gross left ventricular hypertrophy and an echocardiogram showed all the typieal features of hypertrophic obstructive cardiom pathy (Goodwin, 1980). Cardiac catheterization performed with a view to surgery because of heb limiting symptoms. Pressure studies showed subvalvar gradient within the left ventricle at rest of $125-145 \mathrm{mmHg}$ and the left ventricular angiograno showed all the typical features of this condition (Goodwin, 1980). Surgery was advised because i $\overrightarrow{5}$ was felt that the obstruction was so severe thaB medical treatment would not improve her and indeede propranolol before surgery had no clinical effect? Resection of her left ventricular outflow tract wass performed and the only immediate postoperative complication was an episode of supraventriculas tachycardia which settled. Two years after operation? she had an episode of culture-negative infective endocarditis from which she made a good recovery? despite some slight damage to her eighth craniaf nerve probably due to gentamicin. Three years after operation she remained very well with slight breathlessness only, taking frusemide, potassium andू prochlorperazine.

\section{Case 2}

A 65-year-old woman presented with a 4-montho history of increasing angina and breathlessness ando occasional giddy feelings on bending. By the times of presentation her exercise tolerance was 30 yards.? At the age of 25 years she had been refused admission to the Women's Royal Naval Service because of a 
heart murmur. She had no other symptoms and there was no family history of cardiovascular disease. On examination she had a depressed lower sternum and no evidence of heart failure. The arterial pulse had a sharp upstroke, BP was 110/ $80 \mathrm{mmHg}$, there was clinical left ventricular hypertrophy and an ejection systolic murmur was heard all over the praecordium. Chest X-ray showed a large heart with clear lungs. Electrocardiogram showed gross left ventricular hypertrophy and an echocardiogram was not technically possible. The diagnosis was unclear. In view of the possibility of hypertrophic cardiomyopathy and the implications of this diagnosis on management, cardiac catheterization was performed. Pressure studies showed a subvalvar gradient within the left ventricle at rest of $110 \mathrm{mmHg}$ and a left ventricular angiogram showed all the features of hypertrophic obstructive cardiomyopathy. Despite treatment with propranolol, frusemide and potassium, her condition deteriorated over 3 months and so surgical resection of a block of muscle from her interventricular septum was performed. Immediately postoperatively she developed a chest infection which cleared and also became deaf in the left ear, probably owing to an embolus. She was very well 18 months later on no drug therapy.

\section{Case 3}

A 69-year-old woman presented with dizzy spells. These had started 12 years previously. Initially they had lasted for a few seconds and occurred every few weeks. By the time of presentation they were occurring every day and lasted up to $2 \mathrm{hr}$. She had occasional palpitations, became short of breath walking 400 yards on the flat and had 4-pillow orthopnoea and minimal oedema. She had experienced fainting episodes in childhood thought to be due to petit mal, had undergone a hysterectomy and a cholecystectomy and was a chronic bronchitic owing to smoking. After investigations were completed it was discovered that one daughter was already a patient of the same department with a diagnosis of probable hypertrophic cardiomyopathy. On examination, she looked older than her years and was obese. She had a normal quality pulse, BP was $130 / 70 \mathrm{mmHg}$, there was no heart failure and there was clinical evidence of left ventricular hypertrophy. An ejection systolic murmur was heard all over the praecordium. Chest X-ray showed a large heart with clear lungs and there was no calcium in the aortic valve on screening. Electrocardiogram showed gross left ventricular hypertrophy. An echocardiogram was not technically possible because of her obesity. Lung function tests showed a moderate restrictive defect. It was clinically impossible to be sure whether the diagnosis was valvar or subvalvar obstruction so cardiac catheterization was performed. At catheterization there was a subvalvar gradient within the left ventricle of 60 $\mathrm{mmHg}$ at rest. The left ventricular angiogram was highly suggestive of a fixed subaortic stenosis of the 'polo mint' type and so surgery was recommended. Immediately before surgery she had one of her 'dizzy spells' and atrial fibrillation was noted. At surgery no fixed obstruction was found. The appearances on the left ventricular angiogram were thought to be due to the mitral valve impinging on hypertrophied interventricular septal muscle. A block of this hypertrophied muscle was resected. Immediately after the operation she developed a chest infection and atrial fibrillation which responded to treatment. After discharge she remained slightly breathless and had occasional palpitations, but these symptoms responded to disopyramide and a thiazide/amiloride combination. Eight months after operation she was entirely free of symptoms.

\section{Discussion}

These cases are consistent with the American experience that age alone does not contra-indicate operation in this condition (Koch et al., 1980). It was clearly successful, not only in the first 2 cases but also in the third, despite the relative contraindications of atrial fibrillation (Mason et al., 1978), obesity and poor lung function.

Clinical diagnosis was difficult in all patients, not least because of the technical problems with echocardiography. In the third case the distinction between fixed and muscular subvalvar obstruction was only made at surgery and this problem has been reported before (Mason et al., 1978). However, all the patients had clinical and electrocardiographic evidence of gross left ventricular hypertrophy, an ejection systolic murmur and no clinical evidence of previous hypertension or radiological evidence of aortic valve calcification. These findings in symtomatic elderly patients suggest that further investigation and possibly surgery are necessary.

The value of surgery in younger patients with this condition is controversial. Although it can relieve symptoms in the short term, it does not prevent progression of the disease leading to life-threatening arrhythmias and sudden death (Oakley, 1978). This explains why surgery is associated with a poor prognosis (McKenna et al., 1979). However, it is possible that surgery may be more valuable in the management of older than of younger patients. The younger patients who die presumably have more rapidly progressive disease and often die suddenly, presumably owing to life-threatening arrhythmias. Sudden death, however, is less common in older patients (Pomerance and Davies, 1975; McKenna et al., 1979). This condition is congenital, and older 
patients must have disease that progresses more slowly which is why they have survived for so long. They present with disease that is severe enough to cause obstruction, but obstruction, the abnormality that surgery can relieve, is not by itself correlated with life-threatening arrhythmias (Doi et al., 1980). In slowly progressive disease in older patients the interval between obstruction meriting surgery and gross total muscle abnormality causing life-threatening arrhythmias may well be longer than in younger patients.

By contrast, medical management in the elderly is more difficult than in younger patients. Frank et al. (1978) have proposed aggressive medical management using doses of propranolol averaging $462 \mathrm{mg}$ daily, and have suggested that the lack of effect of medical management reported previously (Hadarson et al., 1973) was due to inadequate dosage. The reduced $\beta$-adrenoceptor sensitivity in the elderly (Vestal, Wood and Shand, 1979) and the increased number of adverse reactions to propranolol in the elderly (Greenblatt and KochWeser, 1973) would make such aggressive management particularly difficult. So, while medical management at all ages is unsatisfactory (Shah, 1975), it is more unsatisfactory in older than in younger patients.

Thus, surgical treatment of hypertrophic cardiomyopathy in the elderly is perfectly practical and can be very successful. Medical treatment when the disease is severe can be particularly difficult. As sudden death is unusual in the elderly, perhaps because of slowly progressive disease, the major objection to surgery, that it fails to prevent this complication, does not apply.

\section{Acknowledgments}

I should like to thank Dr C. A. Layton and Mr J. E. C. Wright (case 1), Dr A. H. MacDonald (case 2), Dr P. G. Mills (case 3) and Mr T. Lewis (cases 2 and 3) for permission to report their patients, and Professor H. M. Hodkinson for his helpful advice.

\section{References}

Berger, M., Rethy, C. \& Goldberg, E. (1979) Unsuspected subaortic stenosis in the elderly diagnosed by echocardiography. Journal of the American Geriatrics Society, 27, 178 .
DE Bono, A.H.B., English, T.A.H. \& Milstein, B.B.ळ (1978) Heart valve replacement in the elderly. British ${ }_{C}$ Medical Journal, 2, 917.

DoI, Y.C., McKenna, W.J., Chetty, S., OAKley, C.M. \& Goodwin, J.F. (1980) Prediction of mortality and serious arrhythmia in hypertrophic cardiomyopathy, an echo-음 cardiographic study. British Heart Journal, 44, 150.

Frank, M.J., Abdulla, A.M., Canedo, M.J. \& Saylors, R.E. (1978) Long-term medical management of hyper- $\mathrm{D}$ trophic obstructive cardiomyopathy. American Journal of Cardiology, 42, 993.

Goodwin, J.F. (1979) A current appraisal of the cardio-myopathies. Hospital Update, 5, 665 .

GoodwIN, J.F. (1980) Hypertrophic cardiomyopathy: adisease in search of its own identity. American Journal of $\vec{f}$ Cardiology, 45, 177.

Greenblatt, D.J. \& Koch-Weser, J. (1973) Adverse reaction to propranolol in hospitalized medical patients: a report 3 from the Boston Collaborative Drug Surveillance Program. American Heart Journal, 86, 478.

Hadarson, T., de la Calzada, C.S., Curiel, R.\& Goodwin, J.F. (1973) Prognosis and mortality of hypertrophic obstructive cardiomyopathy. Lancet, ii, 1462.

HochberG, M.S., Morrow, A.G., Michaelis, C.C.ᄋ McIntosh, C.L., Redwood, D.R. \& EPSTEIN, S.E (1977) Aortic valve replacement in the elderly. Archives of Surgery, 112, 1475.

Koch, J.P., Mason, B.J., Epstein, S.E. \& Morrow, A.G@ (1980) Results of operation for obstructive hypertrophiक cardiomyopathy in the elderly. American Journal of Cardiology, 46, 963.

Krasnow, N. \& Stein, R.A. (1978) Hypertrophic cardio myopathy in the aged. American Heart Journal, 96, 386.

McKenna, W.J., Deanfield, J.E., FaruQi, A.M., OAK C.M. \& GoodwIN, J.F. (1979) Prognosis and mortality hypertrophic cardiomyopathy. Circulation, 59/60 (suppi:; II), 154.

Mason, B.J., Merrill, W.H., Frier, P.A., Kent, K.M.S

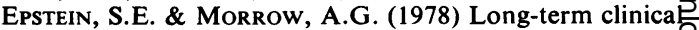
course and symptomatic status of patients after operation for hypertrophic subaortic stenosis. Circulation, 57, $1205 \frac{\text { }}{\mathrm{D}}$

OAKLEY, C.M. (1978) The effect of beta-blockade in hyper trophic cardiomyopathy. In: Modern Aspects of Beta $\vec{F}$ Blocker Therapy (Ed by Birdwood, G.F.B. \& Wink, C.A.S.)? p. 71. Geigy Pharmaceuticals, Macclesfield.

Pomerance, A. \& Davies, M.J. (1975) Pathological features of hypertrophic cardiomyopathy in the elderly. British. Heart Journal, 37, 305.

SHAH, P.M. (1975) Idiopathic hypertrophic subaortic stenosis (hypertrophic obstructive cardiomyopathy) Changing concepts-1975. Chest, 68, 814.

Vestal, R.E., Wood, A.J.J. \& Shand, D.G. (1979) Reduced $\beta$-adrenoceptor sensitivity in the elderly. Clinical Phar macology and Therapeutics, 26, 181.

WyNNE, J. \& BRAUNWALD, E. (1980) The cardiomyopathies? and myocarditides. In: Heart Disease (Ed by Braunwald, E.), p. 1460. W. B. Saunders, Philadelphia. 